"Catch-up" growth growth retardation inanition malnutrition skeleton

\title{
Failure of Compensatory (Catch-up) Growth in the Rat
}

\author{
H. David Mosier, Jr. ${ }^{[29]}$ \\ Iepartment of Pediatries, Liniversity of California, Irvine, College of Medicine; and the Memorial Hospital of Long Beach, \\ Long Beach, California, LS.l
}

\section{Extract}

Growth retardation was produced in rats of the Long-Evans strain, 37-41 days of age, by withholding food, by daily injection of $5 \mathrm{mg}$ cortisone subcutaneously, or by feeding a diet containing $0.1 \%$ propylthiouracil (PTU). 'The duration of fasts were 24,48 , and $72 \mathrm{hr}$ in different experiments. Duration of cortisone or P'TU treatment was adjusted to produce maximum differences in body weight between control and experimental groups that were equivalent to the difference produced in the corresponding fast periods. Serial measurements of body weight and tail length were carried out for 60-80 days from the start of the experimental treatments.

In the fasting experiments, after feeding was resumed the body weight showed a prompt acceleration and nearly complete catch-up during the course of the observations. 'Tail length growth decelerated during fasting and then accelerated on refeeding. This resulted in complete catch-up.

After cortisone treatment there was no catch-up in body weight or tail length growth. After PTU there was a slight tendency to catch-up in body weight and tail length. The latter appeared to show a pattern of late catch-up.

Growth velocity curves for these experiments showed transient changes in growth rates which eventually stabilized by 75 days of age, at about the time the animals became sexually mature.

The results suggest that in the rat cortisone treatment in the postweaning period permanently damages growth mechanisms and prevents grow th recovery in certain circumstances. Hypothyroidism also results in impairment in catch-up growth, but there appears to be some tendency for a delayed catch-up, especially in skeletal growth.

\section{Speculation}

Failure of full catch-up by one part of an organism after transient growth arrest may be the result of either (1) damage to grow th mechanisms of the part or (2) restriction of growth of the part by a control operating to maintain normal proportions in the organism.

\section{Introduction}

A compensatory surge of growth tends to occur during the recovery phase after growth arest in multicellular organisms. The phenomenon, generally called "catch- up growth" in clinical situations, may be observed after short periods of malnutrition or illness [12]. There are, however, circumstances in which catch-up growth occurs only partially or not at all, such as when 
undernutrition occurs during fetal or neonatal life [?, 8 , 19]. Occasionally there is a disappointingly sluggish growth response and failure to gain expected length in the adequately treated cretin. We have also observed a failure of catch-up after total adrenalectomy for long standing, recurrent Cushing's syndrome in a child who still showed x-raly evidence of growth potential; there was an inadequate catch-up growth of height in spite of administration of human growth hormone and thyroxine.

The present experiments in the postweaning period produced failures of catch-up growth of both body weight and tail length in rats after short periods of cortisone injection or propylthiouracil feeding. In parallel experiments with undernutrition, however, catch-up wats almost complete. The findings, which ate discussed, indicate certain complexities in the problem of the control of catch-up growth; and they suggest the usefulness of the laboratory models an analogues of some failures of catch-up that are observed clinically.

\section{Materials and Methods}

One hundred eight mate black hooded rats of the Long-kvans strain [21]. oltatined at at body weight of $60-70 \mathrm{~g}$, were maintained in the animal laboratory of Memorial Hospital of Long Beach. Temperature wats controlled between 21.2-26.7\%. A 14-hr light cycle was maintained. The lats were kept one to a cage in racks with hanging cages, 7 by 7 by 10 inches. The standard diet in the catch-up growth study was bought in powdered form [22] and further reduced in a coffee mill to an even more powdery consistency. The propylthiouracil diet was prepared by addling (i-propylthiomarcil (P'IU) [23] to the powdered standand diet to make a concentration of $0.1 \%$. The mixture was stirred mechanically for 2 hr.

Growth retardation was produced by withholding food, by datily subcutaneous injection of :5 me cortisone acetate [24]. or by feeding the P'I U diet. There were three experiments. The first and third hatd four groups of rats: control, fasted, cortisone-treated, and those fed Pru. The second experinent had only control and fasted rats. The ages of the rats at the beginning of the experiments were 38 datys in experiment $I$, 37 days in experime'nt $I I$, and 11 days in experiment III. The rats were assigned to the groups by rotation from a list of all the animals arranged in order of body weight. This maintained nearly equal means and distributions for the groups at the start of the experiment. The fasted groups in the thee experiments had food withheld for 24,48 , or $72 \mathrm{hr}$, respectively. The corresponding groups (treated with cortisone and fed PTU) were treated until the difference between their mean body weight and mean weight of the control group approxinately equaled the maximal difference between the fasted and control rats. The duration of treatment for cortisone and PTU groups was 4 and 13 days, respectively, in experiment $I$; and 8 and 18 days, respectively, in experime'nt $I I I$. In the first experiment a second 1-day fast was carried out 12 days after the first fast. At that time the fasted group was divided into two subgroups: one wats given six daily injections of $0.5 \mathrm{mg}$ bovine growth hormone [25] in $0.2 \mathrm{ml}$ saline intraperitoneally, and the other wats given daily injections of an equal volume of saline. There was no second treatment with cortisone or PTU in this experiment. All animals survived to the end of the experiment. Food and water were given ad libitum with an excess present al all times except in periods of fasting. Food intake records were kept in all the experiments.

Body weight was measured to the nearest $0.1 \mathrm{~g}$. Tail length was measured to the nearest millimeter according to the method of De ( Froot [3].

\section{Resulls}

Fiast

Velocity of body weight rose after refeeding and became maximal cluring the first 2-4 days [26]. There was nearly complete catch-up of body weight by 57 days in experiment $I I$ and by 60 days in experiment III. Incomplete catch-up occurred in the double lasted group in experiment $I$, but the catch-up was maximal within 5 days of each liast.

Velocity of tail length underwent a steady gain after refeceling and reached the control value at from 7 to 12 days depending on the length of the fast period. In experiment $I I I$ velocity thereafter surpassed that of controls and then decreased gradually during the periods of observation. There wats complete catch-up in tail length.

The administration of growth hormone to some of the l-diy fisted rats of expreriment I had no significant effect on growth of body weight or tail length.

\section{Cortisone:}

Velocity of body weight promptly dropped to nil until injections ceased. It regatined the control value at 8-15 days, depending on the period of injections, and remained at the control level thereafter. The difference in body weight was maintained.

The patterns of tail length were similar to those of 
body weight, although they were more variable. In experiment III normal velocity was regained by 1.1 days. The tail length growth curves, as in the case of the body weight growth curves, showed essentially no catch-up.

\section{$P T U$}

Body weight velocity dropped abruptly on day 1 because of a brief reduction of fool intake, but returned to normal levels in the following measurement interval. Thereafter velocity steadily declined until PTU was discontinued. There was a reversal toward increasing velocity with the velocity curves crossing the control curves at 20-23 days depending on the duration of P'TU feeding. This increase over the velocity of the controls lasted for 10-20 days. The growth curves tended to parallel those of the controls after 16 days in experiment $I$ and 31 days in experiment $I I I$. There was no appreciable catch-up prior to that time in experiment $I$; slight catch-up occurred in experiment III.

Tail length velocity also declined initially and then returned to a normal level at 22-25 days depending on the length of time PTU was fed. Thereafter velocity exceeded control values. This was more marked in experiment III in which PTU was fed longer. The tail length growth curve reflected the changes in velocity and demonstrated a late partial catch-up. In experimenl III the growth curve surpassed that of the cortisone group at about 51 days of the experiment.

Body weight and tail length growth curves for the fasted, cortisone, and PTU groups of experiment III are shown in Figure 1. The corresponding velocity curves are shown in Figure 2.

\section{I)iscussion}

It has been shown that cortisone, undernutrition, and hypothyroidism in the rat prior to weaning produce loss of cells $[1,17,19]$. In the case of undernutrition the growth deficit is reparable by refeeding to a variable extent depending on the time, duration, and severity of undernutrition $[6,18]$. Undernutrition after weaning, however, may be followed by complete (atch-up of body weight, possibly because the growth impairment at the later age involves relatively less reduction in cell number [8]. The present experiments.
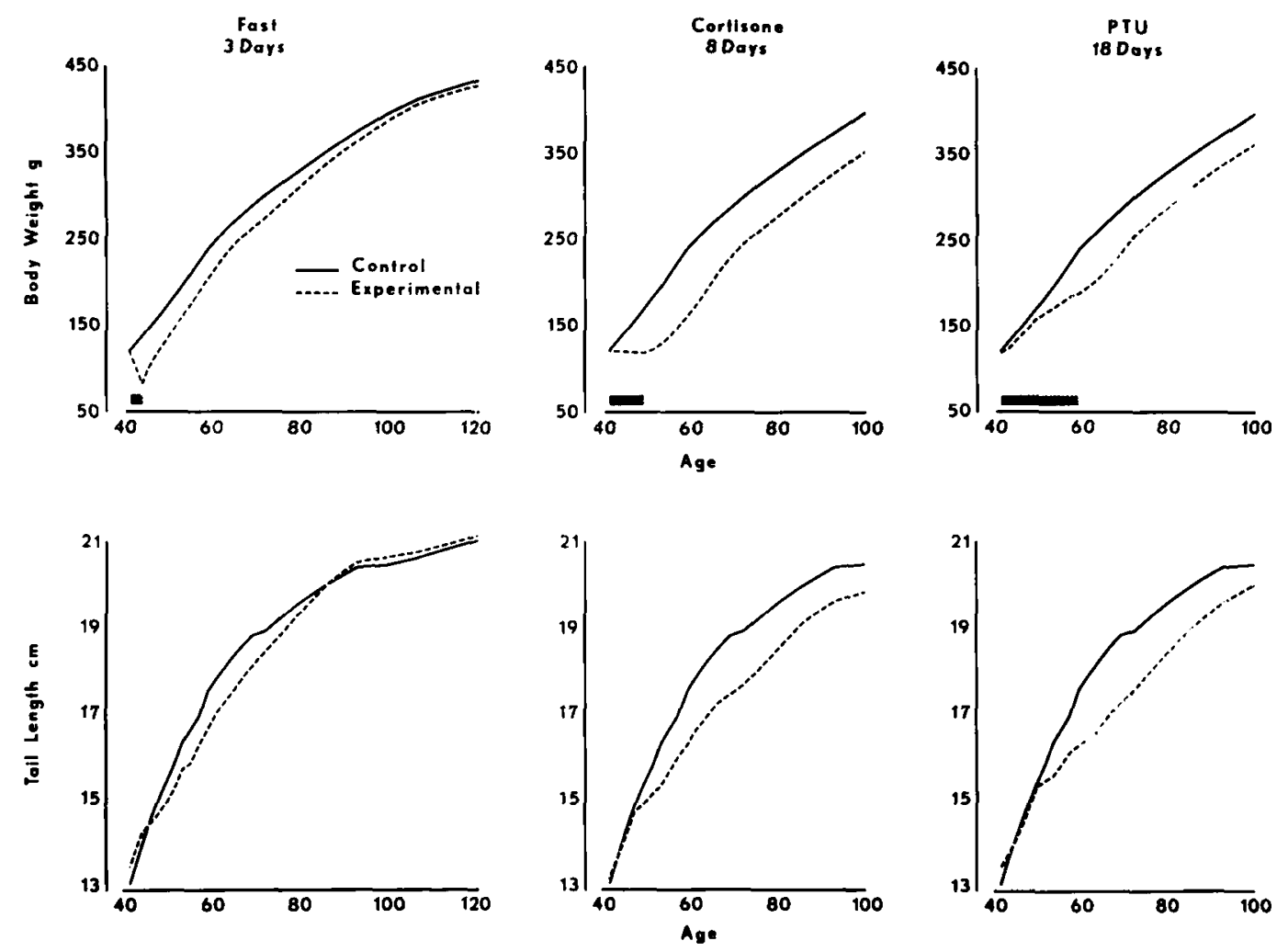

Fig. 1. Body weight and tail Jength growth curves from experiment III. The duration of treatment is shown by the cross-hatched bar on each chart. Age is given in days. 
Growth Velocity
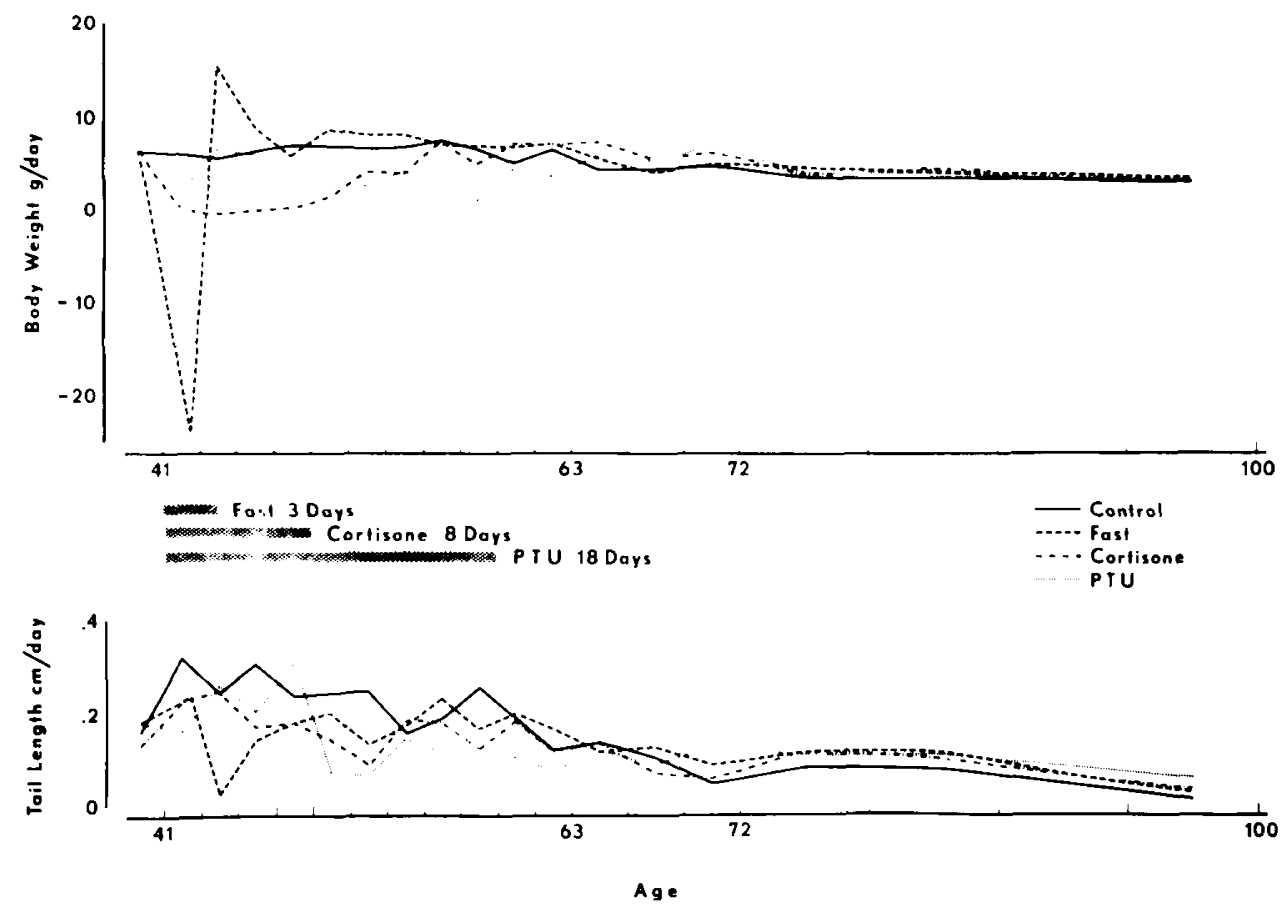

Fig. 2. Growth velecity curves from experiment III. Ige is given in days. The measurement intervals indicated by tics on the abscissa are 2 days from 39 to 6.3 days, 3 days from 6.3 to 72 days, and 7 days from 72 to 100 days of age. The duration of treatments is shown by the cross. hatched bars and their labels.

show that in rats well past weaning and past the main burst of ccll multiplication $[1,20]$ catch-up) growth may not follow growth arrest produced by cortisone or hypothyroidism. Conditions were produced in these experiments that may be analogous to those resulting in inadequate catch-up growth patterns that are sometimes obscrved clinically.

The mechanism by which cortisone produced permanent growth impairment in these experiments is obscure. Treatment of 3 -week-old mice with a dose of $20 \mathrm{mg} / \mathrm{kg} / 2 \mathrm{l} \mathrm{hr}$ for $1-6$ days produces profound changes in chondrocytes, ranging from a decrease in size and a disturbance of organellar development to cell death and fibrillar microscars in the matrix of the subarticular cartilage of the femur [14]. In epiphyscal cartilage of the rat, cortisone produces an early effect of limiting capacity of chondrocytes to self-replicate and a late effect of restricting their modulation toward the osteoblast class [16]. Prolonged disturbance in bone morphology may result, depending on the size of the dose [5]. The ultramicroscopic effects of cortisone on cartilage differ in some respects from those of undernutrition or hypothyroidism [15]. Parenthetically, one might add that since studies of glucose stores or glycolytic enzyme activity show nonspecific reduction after cortisone and several other metabolic states $[7,9$, $10]$ it is necessitry to correlate anatomical and particularly ultrastructural observations of cartilage with biochemical data when interpreting skeletal growth data.

We have reported that alter growth arrest produced by cortisone there is a prompt return to normal proportions between body weight and tail length even when the individual measurements do not catch up [11]. One interpretation of this result is that there may be a separate mechanism governing body proportions. This hypothesis complicates the problem of catch-up growth control by adding the possibility that growth in one dimension may be controlled in order to maintain a certain proportion to another that suffered dam. age to its growth mechanisms. As an example, using our present model, one might conceive that a certain dose of cortisone curtails growth potential of cartilage and this is compensated by the hypothetical control through retandation of growth of other tissues.

Although fasting for only 1 day significantly retards proliferation and growth of chondrocytes [13], nearly 
complete catch-up occurred after even a 3-day fast. By contrast, after propylthiouracil feeding was discontinued, a relatively slow trend of catch-up was seen long after food intake had returned to normal. This is not entirely surprising as cartilage in immature animals responds to hypothyroidism with marked retardation of cellular and organellar development: degenerative changes in mitochondria perhaps indicative of exhaustion have been noted [15].

These results do not permit a conclusion that the different patterns of catch-up are directly related to cartilage changes. They illustrate the complexity of the problem of the mechanism controlling compensatory rates of growth, however, and they suggest that these experimental models may be useful in analyses of growth controls in catchiup growth.

\section{Summary}

Patterns of catch-up growth were investigated after periods of growth arrest were produced in rats of the Long-Evans strain, 37-41 days of age and 102-135 g body weight, by withholding food, injecting cortisone, or feeding propylthiouracil. After lasting there was almost complete catch-up. After short periods of cortisone injections or propylthiouracil feeding complete or partial failure of catch-up growth of both bocly weight and tail length was observed. The experimental models illustrate the complexity of the problem of eluciclating the catch-up growth mechanism: they may also serve as laboratory models of certain failures of catchup growth in the human.

\section{References and Notes}

1. Cimtk, D. B., Powrt., G. K., Mo Scomt, R. E.: Growlt of muscle cells (size and number) and liver DNA in wats and Snell Smith mice with insulficient pituitary, thyosid or testicular function. Bull. Johns Hopkins Hosp., 117: 306 (1965).

2. Chow, B. F., AND LFF, C. J.: Fffect of dietary restriction of pregnant rats on body weight gain in the offspring. J. Nutr., S2: $10(1964)$.

3. D1: (;коoт, 1). A.: Tail growth in the thyroxine-treated hypophysectomized rat as a sensitive criterion for growth hormone activity. Acta Fndocrinol., 42: 423 (I963).

4. ENisco, M., AN1, L.tBlond, (. P.: Increase in cell number as a factor in the growth of the organs and tissues of the young male rat. J. Embryol. Exp. Morphol., 10: 530 (1962).

5. Fol...s, R. H., JR: : Effect of cortisone on growing bones of the rat. Proc. Soc. Exp. Biol. Med., 76: 722 (1951).

6. Guthrif., H. A., And Brown, M. I.: Effect of severe under- nutrition in early life on growth, brain size and composition in adult rats. J. Nutr., $94: 419$ (1968).

7. Kunin, A. S., AND Meyer, W. L.: The effect of cortisone on the internediary metabolism of epiphyseal cartilage from rats. Arch. Biochem., 129: 421 (1969).

8. Maciance, R. A., and Wmoowson, E. M.: Nutrition and growth. Proc. Roy. Soc. Ser. B, Biol. Sci., 156: 326 (1962).

9. Mry.k, W. I., ANI Kunin, A. S.: Decreased glycolytic enzyme activity in epiphyseal cartilage of cortisone-treated rats. Arch. Biochem., 129: 431 (1969).

10. MFYrk, W. L., AND Kunin, A. S.: The inductive effect of rickets on glycolytic enzymes of rat epiphyscal cartilage and its reversal by vitamin $\mathrm{D}$ and phosphate. Arch. Biochem., 129: 438 (1969).

11. Mosir. H. D., JR.: Allometry of body weight and tail length in studies of catch-up growth in rats. Growth, 33: 319 (1969).

12. Prader, A., Tanner, J. M., and von Harnack, G. A.: Catchup growth following illness or starvation. $\Lambda$ n example of developmental canalization in man. J. Pediat., 62: 646 (1963).

13. Sillberiberg, M., Silberberg, R., and Hast.ek, M.: Fffects of fasting and refeeding on the ultrastructure of articular cartilage. Pathol. Microbiol., 30: 283 (1967).

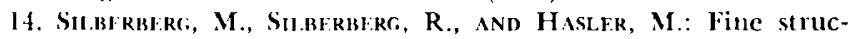
ture of articular cartilage of mice receiving cortisone acetate. Arch. Pathol., 82: 569 (1966).

15. Silbzks:kg, R.: l'Itastructure of articular cartilage in health and disease. Clin. Orthop. Related Res., 57: 233 (1968).

16. Smmons, I). J., ANo Kinis, A. S.: Autoradiographic and biochemical investigations of the effect of cortisone on bones of the rat. Clin. Orthop. Related Res., 55: 201 (1967).

17. Winick, M., AND CosciA, $A$.: Cortisonc-induced growth failure in weomatal rats. Pediat. Res., 2: 451 (1968).

18. Winick, M., Fisti, I., AND Rosso, P.: Cellular recovery in rat tissue after a brief period of neonatal malmutrition. J. Nutr., 95: 623 (1968).

19. Wixick, M., and Nobr., A.: Cellular response in rats during malumtrition at various ages. J. Nutr., 89: 300 (1966).

20. Wixick, M., AND Nobt.F, A.: Quantitative changes in 1$) \times \mathrm{A}$, RNA, and protein during prenatal and postnatal growth in the rat. Develop. Biol., 12: 451 (1965).

21. Simonsen Farme, Cilroy, Callif.

22. (atalog no. 5001-10, Ralston Purina Company, St. Louis, Mo.

23. Mann Rescarch Laboratories, New York, N. Y'

24. Merke, Sharp \& Dohme, West Point, Pa.

25. Kindly supplied by Professor C.. H. I.i.

26. Throughout this section numbers of days refers to days clapsed from the begimning of the experiment unless otherwise stated.

27. The technical assistance of Regina $A$. Jansons is appreciated.

28. Supported by grants from the Memorial Hospital of Long Beach Foundation, the Children's Memorial Iospital Auxiliary, and the Public Health service.

29. Requests for reprints should be addressed to: $H$. David Mosicr, Jr., M.D., 2801 Atlantic Ave., Long Beach, Calif. 90801 (USA).

30. Accepted for publication April $23,1970$. 